\title{
Effects of Plyometric Training to Improve a Physical Capacity and Athletic Performance to High School Students 17-18 Years Old
}

\author{
Houcine Benzidane ${ }^{1, ~ *}$, Habib Bensikaddour², Djamel Mokrani ${ }^{1}$ \\ ${ }^{1}$ Laboratory of Programs Optimization in APS, Institute of Sports and Physical Education, University of Mostaganem, Mostaganem, Algeria \\ ${ }^{2}$ Laboratory of Human Movement Sciences, Institute of Sports and Physical Education, University of Mostaganem, Mostaganem, Algeria
}

\author{
Email address: \\ hocine76ben@yahoo.fr (H. Benzidane)
}

\section{To cite this article:}

Houcine Benzidane, Habib Bensikaddour, Djamel Mokrani. Effects of Plyometric Training to Improve a Physical Capacity and Athletic Performance to High School Students 17-18 Years Old. American Journal of Sports Science. Vol. 3, No. 5, 2015, pp. 98-102.

doi: $10.11648 /$ j.ajss.20150305.14

\begin{abstract}
The research aims to know the effect of implying plyometric method to improve the upgrading capacity and the digital achievement in the effectiveness of the long jump. Where researchers used the experimental method to the nature of research, and the sample consisted of high school students of Relizane province (Algeria). The 56 students were selected and divided into two groups in equal number, while the tests used were the broad jump test of the stability, vertical jump, and digital test achievement in the long jump. After statistical processing of the raw results, the researchers concluded that the use plyometric method in physical education and sports classes for high school students has improved the upgrading capacity, as well as digital achievement in the long jump, in addition to the superiority of the experimental sample over the control sample in the test results. The research finding confirms the effectiveness of using plyometric exercises with students while teaching in improving the digital achievement with the experimental research sample.
\end{abstract}

Keywords: Plyometric Method, Upgrading Ability, Digital Achievement, Long Jump

\section{Introduction}

The long jump occupies a prominent place among the field competitions where it is practiced by all ages and represents the combined competitions. It seems they are easiest competition jumps while researchers see it as the most difficult races where the ricer can advance digitally view of the challenges faced him during the performance and where he should transfer horizontal speed to the center of gravity to a vertical speed at the moment upgrading to have the least possible gained speed from approaching. Modern sports training programs as well as the used methods in their subunits, whether monthly, weekly or even daily are full with what is new [1]. The plyometric style is the latest general training methods to all sport activities. Also, a lot of researchers see that plyometric training is the most commonly used in explosive power development and distinctive speed force for many sport activities, which require the integration of the maximum speed with maximum force of muscle, where this method contribute in overcoming the problems that correspond to force development. This is what was said by
Hamdi Sofiane (2011) [2], Markovic, G (2007) [3], that plyometric training contribute to the improvement of achievement, especially in activities that use explosive muscular contractions, and Ramírez-Campillo (2005) [4], who pointed out that the plyometric training in the short term is effective to the development of strength muscle, upgrading and anaerobic capacity. In contrast, he adds that connecting plyometric training exercises with the adoption of loads becomes very effective with the players $[5,6]$. Plyometric training is considered as one of the development methods of the explosive power of the legs and the working muscles on the joints of the lower parts (legs), as well as the improvement and development of normal and broad jump distance. They do not get a great deal of research in spite of the importance posed by the explosive power of the working muscles on the lower parts as well as the improvement and development plyometric in various activities, including the long jump. The research results indicated that plyometric training is effective and efficient way to improve the strength and speed of movement. Such as the study of Caruso, J. F, et al. (2010) [7], Kotzamanidis (2005) [8], Estriga, L., et al. [9], where it is clear 
that the use of plyometric training is an effective factor in the long jump competition, which performance requires to work on the integration of maximum force of muscles with the speed performance to achieve a high degree recipe performance capability especially if the explosive power of the legs is one of the qualities of desired development.

It is understood that the primary objective in physical education and sports lessons in secondary level is upgrading physical level for students, so they can practice practical lessons with a good level of fitness, and through field followup to some of the lessons. The weakness was observed in the fitness and motor performance among students in the long jump, with a lack of divers ification and combination of modern methods of training by professors, particularly in the development of effective physical attributes. This is what made us note the weakness of digital achievement in the long jump among students. Therefore, the researchers decided to know the effect of implying plyometric method to develop the upgrading capacity to improve the digital achievement in the long jump with students in physical education and sports classes at the secondary level (High School).

\section{Methodology}

\subsection{Research Methodology}

The appropriate experimental method was followed due to the nature of the research problem.

\subsection{Research Sample}

The research community was students of the third year of secondary school (17-18 years) only the male gender. The researchers selected a sample of 56 students, divided into an experimental sample of 28 students and a control sample of 28 students, having the same level of physical abilities.

\subsection{Specification Tests}

Test (01): Vertical jump test.

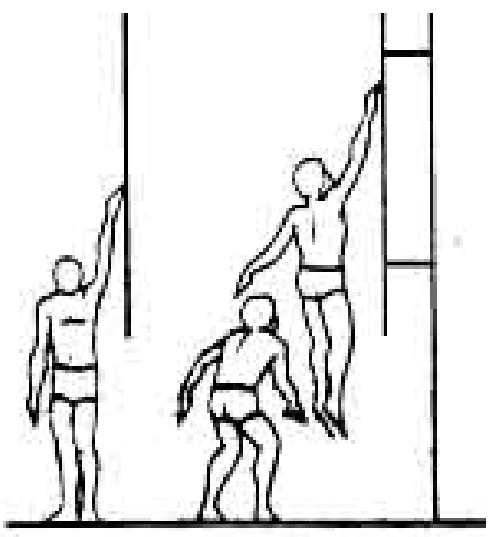

Figure (01). Shows the Vertical jump test.

The purpose of the test: Measuring muscle strength of the legs.

Tools: Chalk, measuring tape, wall.
Performance specifications: The student stands next to the wall and extends his arms to the top in order to determine the brand with chalk. Then he moves arms, bends forward and down, bends his knees and then jump towards the top to determine the second mark.

Recording: The distance is measured between the two brands in centimeters.

Test (02): The broad jump test of stability.

- The goal of the test: Measuring the explosive force of the muscles of the legs.

- Used instruments: Flat land, tape to measure the distance.

- Description of performance: Installing the measuring tape on the flat land, the experimenter stands behind the starting line. He bends his knees, returns the arms to the back, jumps to the farthest distance, and gives to the experimenter two attempts and calculates the best.

- Recording: The distance is measured by meters from the starting line even closer to the impact of the foot from the starting line.

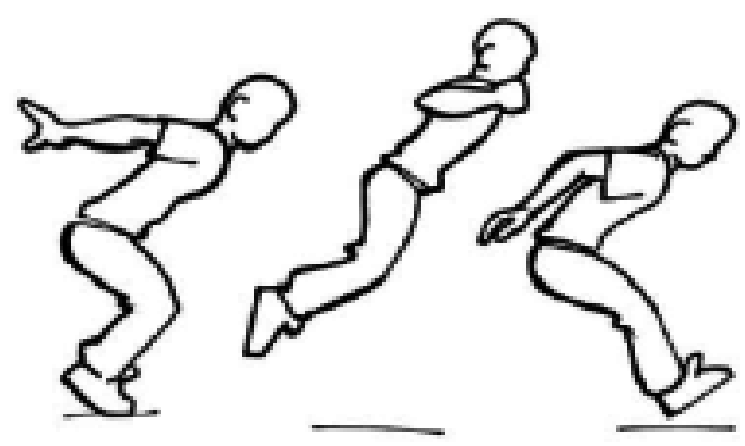

Figure (02). Shows the broad jump test of stability.

Test (03): The long jump test.

- The purpose of the test: Measuring the achievement of the long jump distance.

- Instruments used: Tape to measure the distance, long jump track.

- Description of performance: Every athlete was selected after the control of the approximate distance to the advancement board. Three attempts are given for each athlete and recorded the highest achievement in the form. The distance is measured to the last trace left by the athlete.

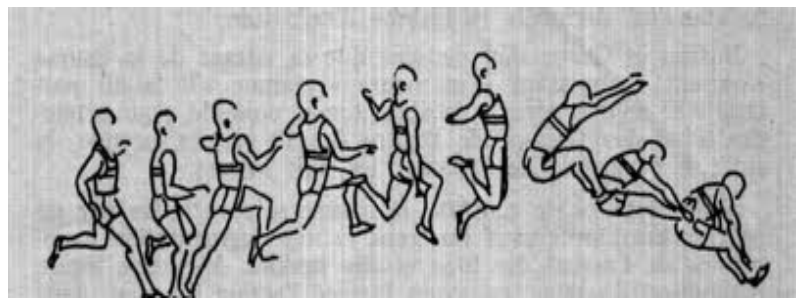

Figure (03). Shows the long jump test.

\subsection{Basic Experience}

The sessions were conducted during the lesson of physical 
education and sports for the research sample, a set of plyometric exercises were used to develop the capacity to upgrading and performance in the effectiveness of the long jump, using the necessary tools, means and the selection of appropriate plyometric exercises to achieve the objectives of the research.

The 10 educational units were proposed implying plyometric method in physical and sports education classes at the secondary level, by units a week for 20 minutes of total class time, beginning from Jan. $06^{\text {th }}, 2014$ to Mar. $10^{\text {th }}, 2014$, the same major and minor procedural goals with the control and experimental research samples.

\subsection{Discussion of the Results}

Viewing, analyzing and discussing the vertical jump test results " Sargent":

Table (01). Independent sample t-test comparisons between the pre-test and post-test results in the vertical jump variable ( $\left.{ }^{*} p \leq 0.05\right)$.

\begin{tabular}{llllllll}
\hline Statistical measurements & Pre-test & \multicolumn{3}{c}{ Post-test } & \multirow{2}{*}{ T Calculated } & \multirow{2}{*}{ T Tabular } & \multirow{2}{*}{ Progress rate } \\
\cline { 2 - 5 } Sample & $\mathbf{X 1}$ & Y1 & X2 & Y2 & & & $13.98 \%$ \\
Experimental sample & 39.33 & 5.04 & 44.83 & 4.49 & $9.77^{*}$ & 2.05 & $06.05 \%$ \\
Control sample & 35.67 & 07 & 37.83 & 7.11 & $2.17^{*}$ & \\
\hline
\end{tabular}

*indicates significant difference $(\mathrm{P}<0.05)$ from baseline

We note from the table $(01)$, the presence of significant differences between the pre and post measurement in favor of telemetric in the vertical jump test with the experimental and control samples where the estimated calculated $\mathrm{T}$ is respectively 9.77 and 2.17 . It is the largest of the estimated tabular by 2:05 at the level of 0.05 and the degree of freedom 27.

Viewing, analyzing and discussing the broad jump test:

Table (02). Independent sample t-test comparisons between the pre-test and post-test results in the broad jump variable $\left({ }^{*} p \leq 0.05\right)$.

\begin{tabular}{|c|c|c|c|c|c|c|c|}
\hline \multirow{2}{*}{ Statistical measurements Sample } & \multicolumn{2}{|c|}{ Pre-test } & \multicolumn{2}{|c|}{ Post-test } & \multirow{2}{*}{ T Calculated } & \multirow{2}{*}{ T Tabular } & \multirow{2}{*}{ Progress rate } \\
\hline & X1 & Y1 & X2 & Y2 & & & \\
\hline Experimental sample & 1.9 & 0.22 & 2.14 & 0.14 & $2.81 *$ & \multirow{2}{*}{2.05} & $8.62 \%$ \\
\hline Control sample & 2.0 & 0.09 & 2.07 & 0.08 & $4.47 *$ & & $2.98 \%$ \\
\hline
\end{tabular}

* indicates significant difference $(\mathrm{P}<0.05)$ from baseline

We note from the table (02), the presence of significant differences between the pre and post measurement in favor of telemetric in the vertical jump test with the experimental and control samples where the estimated calculated $\mathrm{T}$ is respectively 2.81 and 4.47 . It is the largest of the estimated tabular by 2,05 at the level of 0.05 and the degree of freedom 27.

Viewing, analyzing and discussing the long jump test:

Table (03). Independent sample t-test comparisons between the pre-test and post-test results in the long jump variable $\left({ }^{*} p \leq 0.05\right)$.

\begin{tabular}{|c|c|c|c|c|c|c|c|}
\hline \multirow{2}{*}{ Statistical measurements Sample } & \multicolumn{2}{|c|}{ Pre-test } & \multicolumn{2}{|c|}{ Post-test } & \multirow{2}{*}{ T Calculated } & \multirow{2}{*}{ T Tabular } & \multirow{2}{*}{ Progress rate } \\
\hline & $\mathbf{X 1}$ & Y1 & $\mathbf{X 2}$ & Y2 & & & \\
\hline Experimental sample & 4.03 & 0.27 & 4.30 & 0.19 & $3.27 *$ & \multirow{2}{*}{2.05} & $6.07 \%$ \\
\hline Control sample & 3.88 & 0.51 & 4.04 & 0.54 & $2.53 *$ & & $04.12 \%$ \\
\hline
\end{tabular}

* indicates significant difference $(\mathrm{P}<0.05)$ from baseline

We note from the table (03), the presence of significant differences between the pre and post measurement in favor of telemetric in the vertical jump test with the experimental and control samples where the estimated calculated $\mathrm{T}$ is respectively 3.27 and 2.53 . It is the largest of the estimated tabular by 2,05 at the level of 0.05 and the degree of freedom 27.

Comparison of post-test results of research samples:

Table (04). Independent sample t-test comparisons between experimental and control sample (*p $\leq 0.05)$.

\begin{tabular}{|c|c|c|c|c|c|c|}
\hline \multirow{2}{*}{ Statistical measures Test } & \multicolumn{2}{|c|}{ Control sample } & \multicolumn{2}{|c|}{ experimental sample } & \multirow{2}{*}{ T calculated } & \multirow{2}{*}{ T tabular } \\
\hline & $\mathbf{X}$ & $\mathbf{Y}$ & $\mathbf{X}$ & $\mathbf{Y}$ & & \\
\hline vertical jump & 37.66 & 7.11 & 44.83 & 4.49 & $2.70 *$ & \\
\hline Broad jump test of stability & 2.19 & 0.19 & 2.34 & 0.12 & $3.61 *$ & 02.00 \\
\hline Achievement test & 4.60 & 0.40 & 4.85 & 0.33 & $2.55^{*}$ & \\
\hline
\end{tabular}

* indicates significant difference $(\mathrm{P}<0.05)$ from baseline

It is observed from the table (04) after the use of test $\mathrm{T}$ student that ranges between 2.55 and 3.61, the largest values of tabular $\mathrm{T}$ is estimated at 2.00 at a degree of freedom 54 and the significance level is 0.05 . It confirms the existence of significant differences between the averages of any developments, which means that the differences between the averages have statistical significance. 


\section{Discussion of the Results}

Researchers conclude from the vertical jump test results and the broad jump test from the stability recorded in the tables $(01)$ and (02), that implying plyometric method in the physical education and sports classes at the secondary level on the experimental sample had a positive impact in improving the ability to upgrade and forward. The students have an important physical attributes for practitioners of the long jump. The plyometric exercises elaborate to improving the movement energy and elastic energy that have a significant impact on the ability of the explosive development by prolongation and dereliction of muscle fibers cycle.

Therefore, the experimental sample achieved the best results compared to the control sample in a test for the vertical jump in height and broad jump at stability. This is due to the effect of plyometric exercise by selecting the appropriate exercise (appropriate redundancy and density as well as the intensity). According Zatsiorsky, V. M. (1995), plyometric training is much focused activity which requires a high resolution of interaction with the nervous system [10]. It is confirmed by many studies [11, 12, and 13] in this regard, that the importance of plyometric exercise through improving each component of muscle strength and speed at the same time and that show the explosive form. So, the plyometric exercises are factors which led to increase the explosive power of the legs, especially in the jump competitions, where research results have shown that plyometric training is impressive and effective way to improve the strength and movement speed $[14,15,16$, and 17].

The results of table (03) also show that the digital achievement test of the long jump, the calculated $\mathrm{T}$ is estimated at 3.72 with experimental sample and 2.53 for the control sample which is a bigger than tabular value 2.05 . It means that respondents have achieved the best results in a posteriori measurements compared to members of the control sample. This is due to the implying plyometric exercises on the experimental sample with a view to the development of explosive power of the lower parts and thus upgrading capacity to improve digital achievement in the long jump. It confirmed the effective impact on the muscular system through the development of the relationship between the distinctive power and the explosive power of the lower parts. Thus, the development of upgrading capacity improved digital achievement in the game. This is in line with what is indicated by a number of studies [18, 19, and 20] that the plyometric training contribute to improving achievement specially in activities that use muscular explosive contractions [21], who pointed out that the plyometric training is effective in the short term for the development of muscle strength and upgrading. In addition to what was said by Matavulj \& al (2001) [23], and Wilson, G., et al, (1996) [24] that the plyometric training improved the results of jumping and leaping to the basketball players, for example, and what was pointed out by Kotzamanidis (2006) [25], that plyometric training developed a delivery process in the vertical jump with young people.

Therefore, the researchers believe that upgrading is essential to the effectiveness of the long jump and it is shown clearly in the table (04) by student results in tests (vertical jump up, jump broad stability and digital achievement test in the long jump) where the values of $\mathrm{T}$ between 2.40 and 3.71 which is greater than the value of tabular $\mathrm{T}$ estimated at 2.00. This reflects the degree of interdependence between upgrading and achievement. Therefore, the development in the results of progress was the result of the use of the scientific basis in training while dealing with students in the effectiveness of the long jump through the appropriate increase in the training loads, the period of time, the continuity of exercise, the repeat of exercise and the training period.

\section{Conclusions}

Physical education and sports educational is process aimed at finding a good citizen who his country depends upon him. It has become a concern for the individual in various fields to achieve the educational objectives of the sports at various levels for the development of intellectual and motor performance. There are a lot of methods used and applied to the students what led us to imply plyometric method in physical education and sports lessons at the secondary level, in order to know the effect of using this method to students through carrying out pre and post measurements of both control and experimental samples as it was applied to the former the school scheduled program, while the experimental sample involved plyometric exercises. After statistical processing of the results, it was shown that the plyometric method contributed to improving the upgrading capacity and achievement in the long jump among students with the superiority of the experimental sample compared to the control sample. This is indicated by the studies of de Villarreal, E. S.S., et al. (2009) [26], Saez de Villarreal, E., et al. (1993) [27], Adams, K., et al. (1992). [28], Holcomb, W., et al. (1996 b), [29], Stojanović, and Kostić, (2002) [30], that the plyometric training in the short term is effective to the development of muscle power and contributes to the achievement of physical education and sports activities using explosive muscle contractions. The result findings confirms the effectiveness of using plyometric exercises in physical education and sports lessons for students and led to an improvement in the digital achievement with the experimental research sample.

\section{References}

[1] Weineck, J. (2000). Optimales training (Optimal training). 11. Auflage. Balingen: Spitta Verlag GmbH.

[2] Hamdi Sofiane. (2011) Effect of two méthods entrainement, plyométric and musculation, on Explosive by players of Soccer Canada, Université du Québec à Montréal.p 02.

[3] Markovic, G., Does plyometric training improve vertical jump height? A meta-analytic review. British Journal of Sports Medicine, 2007. 
[4] Ramírez-Campillo, R., D. C. Andrade, and M. Izquierdo, Effects of Plyometric Training Volume and Training Surface on Explosive Strength. The Journal of Strength \& Conditioning Research, 2013. 27(10): p. 2714-2722 10.1519/JSC. 0b013e318280c9e9.

[5] Markovic, G., et al., Effects of sprint and plyometric training on muscle function and athletic performance. The Journal of Strength \& Conditioning Research, 2007. 21(2): p. 543-549.

[6] Ferreira, L. C., Schilling, B. K., Weiss, L. W., Fry, A. C., and Chiu, L. Z. F. (2010). Reach height and jump displacement: Implications for standardization of reach determination. Journal of Strength and Conditioning Research 24: 1596-1601.

[7] Caruso, J. F., Daily, J. S., McLagan, J. R., Shepherd, C. M., Olson, N. M., Marshall, M. R., and Taylor, S. T. (2010). Data reliability from an instrumented vertical jump platform. Journal of Strength and Conditioning Research 24: 2799-2808.

[8] Kotzamanidis, C., et al., The effect of a combined highintensity strength and speed training program on the running and jumping ability of soccer players. The Journal of Strength \& Conditioning Research, 2005. 19(2): p. 369-375.

[9] Estriga, L., Carvalho, J., Bernardes, J., and Massada, L. (2009). Jump capacity and the ACL injury in female handball players. 14th Annual Congress of the European College of Sport Science in Oslo, Norway from 24-27 June 2009. Book of Abstract. p. 68.

[10] Zatziorsky, V. M. (1995). Science and practice of strength training. Champaign, Il. "Human Kinetics".

[11] Šibila, M., Pori, P., and Bon, M. (2003). Basic kinematic differences between two types of jump shot techniques in handball. Acta Universitatis Palackianae Olomucensis Gymnica 33: 19-26.

[12] Nicole J chimera, Kathleen A Swanik. Effects of plyometric training on muscle-activation strategies and performance in female athletes. Journal of athletic training 2004. 24-31.

[13] Roopchand-Martin, P Lue Chin. Plyometric training improves power and agility in jamaicas national netball team. West indian medical journal. 2010. 1-12.

[14] Cherif, M., Said, M., Chaatani, S., Nejlaoui, O., Gomri, D., and Abdallah, A. (2012). The effect of a combined highintensity plyometric and speed training program on the running and jumping ability of male handball players. Asian J Sports Med 3: 21-28.

[15] Laura H Moore, Michael J Tankovich. kinetic analysis of four plyometric push up vairations. International journal of exercise science. 2012. 334-343.

[16] Jeffery E Vossen, John E Kramer. Comparison of dynamic push-up training and plyometric push-up training on upper body power and strength. National strength and conditioning association 2000. 248-253.

[17] Rahimi, R., \& Behpur, N. (2005). The effect of plyometric, weight and plyometric-weight training on anaerobic power and muscular strength. Facta Univ Phys Educ Sport, 3(1), 8191.
[18] Chu, Donald. (1983). polymétries, the Link between strength and speed, rome: p3, 4 .

[19] Kopper, B., Ureczky, D., and Tihanyi, J. (2012). Trunk position influences joint activation pattern and physical performance during vertical jumping. Acta Physiol Hung 99: 194-205.

[20] Bryan C. Heiderscheit, Karen Palmer Mclean. The effects of isokinetic versus plyometric training on the shoulder internal rotators. Journal of orthopedic and sports physical therapy. 1996. 125-133.

[21] Andrew B Carter, Thomas W Kaminski. Effects of high volume upper extremity plyometric training on throwing velocity and functional strength ratios of the shoulder rotators in collegiate baseball players. Journal of strength and conditioning research 2007. 208-215.

[22] Swanik KA, Lephart SM, Swanik CB, Lephart SP, Stone DA, $\mathrm{Fu} \mathrm{FH}$. The effects of shoulder plyometric training on proprioception and selected muscle performance characteristics. J Shoulder Elbow Surg. 2002;11:579-586

[23] Matavulj, D., Kukolj, M., Ugarkovic, J., Tihanyi, J. and Jaric, S.)2001). "Effects of Plyometric training on jumping performance in junior basketball players". Journal of Sports Medicine and Physical Fitness 41,159.

[24] Wilson, G., Murphy, A., \& Giorgi, A. (1996). Weight and plyometric training: Effects on eccentric and concentric force production. Canadian Journal of Applied Physiology, 21, 301315 .

[25] Kotzamanidis, C.) 2006). "Effect of Plyometric training on running performance and vertical jumping in prepubertal boys". Journal of Strength and Conditioning Research 20, 441- 445.

[26] De Villarreal, E. S.-S., et al., Determining variables of plyometric training for improving vertical jump height performance: a meta-analysis. The Journal of Strength \& Conditioning Research, 2009. 23(2): p. 495-506.

[27] Saez de Villarreal, E., et al., Enhancing sprint and strength performance: combined versus maximal power, traditional heavy-resistance and plyometric training. J Sci Med Sport, 2013. 16(2): p. 146-50

[28] Adams, K., O’Shea, J., O'Shea, K., \& Climstein, M. (1992). The effect of six weeks of squat, plyometric, and squatplyometric training on power production. Journal of Applied Sports Science Research, 6, 36-41.

[29] Holcomb, W., Lander, J., Rutland, R., \& Wilson, G. (1996b). The effectiveness of a modified plyometric program on power and the vertical jump. Journal of Strength and Conditioning Research, 10, 89-92.

[30] Stojanović, T., \& Kostić, R. (2002). The effects of the plyometric sport training model on the development of the vertical jump of volleyball players. Facta Univ Phys Educ Sport, 1(9), 11-25. 